\section{Introduction to the ISBN System}

The question of the need and feasibility of an international numbering system for books was first discussed at the third International Conference on Book Market Research and Rationalization in the Book Trade, held in Berlin in November 1966. At that time, a number of European publishers and book distributors were considering the use of computers for order processing and inventory control, and it was evident that a prerequisite for an efficient automated system was a unique and simple identification number for every published item. The system which fulfilled this requirement and which became known as the International Standard Book Number (ISBN) System was developed out of the Standard Book Number System introduced in the United Kingdom in 1967. In 1968, the Technical Committee on Documentation of the International Organization for Standardization (ISO / TC 46) set up a working party to investigate the possibility of adopting the British system for international use. During 1968 and 1969, several meetings took place between representatives from various European countries and the United States of America. The International Standard ISO 2108, which sets out the principles and procedure for international standard book numbering, resulted from these meetings. The purpose of the international standard is to coordinate and standardize internationally the use of ISBNs with the intent to identify one title, or one edition and/or format of a title, from one specific publisher.

\section{The Scope of the ISBN}

The International Standard Book Number (ISBN) is a 13-digit number that identifies unambiguously and globally any monographic publication. The ISBN accompanies the book from production through distribution to sale. Therefore, it contributes considerably to the rationalization of the book distribution systems. The introduction of the ISBN led to the simplification of ordering, stock control, accounting, and export procedures in the book industry supply chain. The ISBN also facilitates ordering, acquisition, cataloguing, and circulation procedures in libraries and documentation centres, even across political borders. The introduction of the ISBN system thus serves the flow and documentation of bibliographic information and provides economic bibliographic control of the national book production. In addition, the ISBN contributes to more efficient marketing of books. It identifies not only a product, but also its publisher, whose contact details are given in this publication.Publishers' International ISBN Directory
Examples of types of monographic publications to which an ISBN may be assigned are:

- Printed books and pamphlets (and their various product forms)

- Braille publications

- Educational/instructional films, videos and transparencies

- Audio books on cassette or CD or DVD (talking books)

- Electronic publications either on physical carriers or on the internet

- Microform publications

- Educational or instructional software

- Mixed media publications where the principal constituent is text-based

Examples of the types of material to which an ISBN shall not be assigned are:

- Continuing resources (e.g. serials, series without predetermined conclusion)

- Ephemeral printed materials such as advertising matter and the like

- Printed music

- Art prints and art folders without title page and text

- Personal documents (such as electronic curriculum vitae and personal profiles)

- Greetings cards

- Music sound recordings

- Software that is intended for any purpose other than educational or instructional Games

For the numbering of printed music an International Standard Music Number (ISMN), technically a subset of ISBN, was established. The standard for an International Standard Music Number (ISMN) was published in 1993 (ISO 10957). The registration authority is:

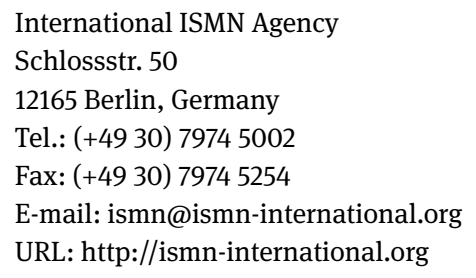

Newspapers and periodicals (continuing resources) are covered by the International Standard Serial Number (ISSN). Information on this system is provided by the national ISSN centres or by: 
ISSN International Centre

45 rue de Turbigo

75003 Paris, France

Tel (+33 1) 44882220

Fax (+33 1) 40263243

E-mail: issnic@issn.org

URL: www.issn.org

\section{Structure of the International Standard Book Number (ISBN)}

Since 1 January 2007, following the revision of the ISBN standard, ISBNs always consist of 13 digits, comprising the following elements:

- Prefix element

- Registration group element

- Registrant element

- Publication element

- Check digit

When printed the ISBN is always preceded by the letters "ISBN".

The ISBN is divided into five elements, three of them of variable length; the first and last elements are of fixed length. The elements must each be separated clearly by hyphens or spaces when displayed in human readable form:

ISBN 978-0-571-08989-5 or

ISBN 9780571089895

The number of digits in the second, third, and fourth elements of the ISBN (registration group element, registrant element, publication element) varies. The length of the registration group element and of the registrant element is relative to the anticipated publishing output of the registration group or registrant. When these elements are short in length it indicates that the output of the registration group or the registrant (or both) is expected to be a large number of publications.

\section{Part 1 - Prefix Element}

The first element of the ISBN is a three-digit number that is made available by GS1 (formerly EAN International). Prefixes that have already been made available by GS1 are 978 and 979 , but there may be a further prefix allocation made in the future as required to ensure the continued capacity of the ISBN system.

Example: 978-0-11-000222-4

\section{Part 2 - Registration Group Element}

In combination with the prefix element the second element of the ISBN identifies the country, geographical region, or language area participating in the ISBN system. Some members of the ISBN system form language areas (e.g., registration group number 978-3 = German language group); others form regional units (e.g., registration group number 978-982 = South Pacific). The length of this element varies but may comprise up to 5 digits.

Registration group elements are allocated by the International ISBN Agency.

Example: 978-0-11-000222-4

\section{Part 3 - Registrant Element}

The third element of the ISBN identifies a particular publisher or imprint within a registration group. The length of this element varies in direct relationship to the anticipated output of the publisher and may comprise up to 7 digits. Publishers with the largest expected title outputs are assigned the shortest registrant elements and vice versa.

Potential registrants apply to the ISBN registration agency responsible for the management of the ISBN system within the country, region, or language group where they are based in order to be assigned registrant elements that are unique to them. Once they have exhausted the allocation of ISBNs that is linked to their registrant element, they may be assigned an additional registrant element to provide them with fresh allocations of ISBNs.

Example: 978-0-11-000222-4

\section{Part 4 - Publication Element}

The fourth element of the ISBN identifies a specific edition of a publication by a specific publisher in a particular format. The length of this element varies in direct relationship to the anticipated output of the publisher concerned and may comprise up to 6 digits. Publishers with the largest expected title outputs are assigned the longest publication elements and vice versa.

Example 978-0-11-000222-4

\section{Part 5 - Check Digit}

The fifth element of the ISBN, the final digit, is the check digit. This is calculated using a modulus 10 algorithm.

Example 978-0-11-000222-4 


\section{Display of the ISBN}

The ISBN must appear on the product itself. This is essential for the efficient operation of the system. In the case of both printed and digital publications, the ISBN must appear on the verso of the title page or, if this is not possible, at the foot of the title page itself. It must also appear at the foot of the outside back cover if practicable, or be printed in some other prominent outside position. The size of type used for printing must not be less than 9 point $(=3.38 \mathrm{~mm})$.

\section{EAN Bar Codes for Books}

An agreement between GS1 (formerly known as the International Article Numbering Association, EAN) and the International ISBN Agency permits the conversion of the ISBN into an EAN/UPC bar code. The contract was concluded with the International Article Numbering Association (EAN) in 1980 and was renewed with GS1 in 2005. It lays down that publishers using the EAN/UPC barcode do not have to apply for the allocation of a manufacturer number by the responsible GS1 numbering authority. There are no fees for publishers using EAN/UPC barcodes based on ISBNs. Publishers only have to pay for the barcode film master which they may order directly from a manufacturer.

When used in a bar code, the ISBN must be displayed in human readable form, with hyphens, immediately above the EAN-13 bar code symbol, preceded by "ISBN". Example of printing the ISBN 978-0-11-000222-4 in EAN-13 bar code symbol symbology:

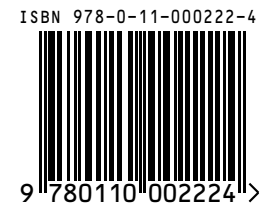

\section{Administration of the ISBN System: International ISBN Agency}

The international administration and coordination of the ISBN system is carried out by:

\author{
International ISBN Agency \\ c/o EDItEUR \\ United House, North Road \\ London N7 9DP, UK \\ Tel: +44 (0)20 75036418 \\ Fax: +44 (0)20 75036418 \\ E-mail: info@isbn-international.org \\ URL: www.isbn-international.org
}

The principal functions of the International ISBN Agency are: to approve the definition of registration groups, to allocate group numbers to the individual ISBN registration agencies, and to advise ISBN registration agencies. The International Agency is also responsible for any assistance with the establishment of the ISBN system and of ISBN registration agencies in individual countries, the general supervision and further development of the system, and worldwide promotion of the ISBN system.

\section{ISBN Registration Agencies}

The administration of the ISBN system within a registration group is the duty of an ISBN registration agency, which may operate on a national or regional basis or within a linguistic group according to local needs. In cooperation with the publishers in the area and with the International ISBN Agency, the registration agencies establish the range of registrant elements commensurate with the extent of a region's publishing industry. They also promote participation in the ISBN system within their area, provide suitable information material, assign individual registrant elements, and advise publishers as to the correct application of the ISBN system. In their area the ISBN registration agencies are responsible for the faultless functioning of the system. They are in regular contact with the International ISBN Agency and report on the development of the system in their respective area.

\section{Publishing Houses}

Publishers are responsible for assigning ISBNs to the individual items they publish and for ensuring the application of pertinent regulations. Upon request they may receive a registrant element from the respective ISBN registration agency and, if desired, a listing of the ISBNs that are available to them in combination with the allocated registrant element.

Further information and detailed instructions are available from the ISBN registration agencies (www. isbn-international.org/agencies) and from the International ISBN Agency. 